\title{
A common prosthetic valve at uncommon position
}

\author{
Bhupinder Singh, Yadvinder Singh, Vivek Singla, Manjunath C Nanjappa
}

Department of Cardiology, Sri Jayadeva Institute of Cardiovascular Sciences and Research, Bangalore, Karnataka, India

\section{Correspondence to}

Dr Yadvinder Singh, dryadvinder@hotmail.com
To cite: Singh $B$, Singh $Y$, Singla $V$, et al. BMJ Case Reports Published online: [Please include Day Month Year] doi:10.1136/bcr-2012008146

\section{DESCRIPTION}

An 11-year-old boy underwent tetralogy of Fallot's repair at the age of 1 year. He was doing well after repair till the age of 5 years when he developed gradually progressive dyspnoea on exertion. Patient developed atrial fibrillation. At the age of 7 years, he underwent pulmonary valve replacement (PVR) with a TTK Chitra (tilting disc prosthetic valve) mechanical heart valve prosthesis in view of severe pulmonary regurgitation with moderate right ventricular dysfunction. Now, the patient has come for follow-up and is doing well. Chest radiography posteroanterior view (figure 1A) revealed metallic ring shadow (black arrows) which on lateral view (figure 1B) was confirmed to be in reterosternal pulmonary position. Two-dimensional echocardiogram revealed mechanical prosthetic valve with acoustic shadowing (black arrow) in pulmonary position on parasternal short axis view (figure 2A, videos 1 and 2). Doppler interrogation (figure 2B) showed Doppler signals (white arrows) of opening and closure of mechanical prosthetic valve. Patient is on oral anticoagulation with adequately maintained international normalised ratio.

Tetralogy of Fallot is at risk of failure of their right ventricle, ${ }^{1}$ mostly because of pulmonary regurgitation induced by a transannular patch. Even though the bioprosthetic prosthetic valves are preferred for PVR, still, mechanical prosthetic valve usage is justified in patients requiring anticoagulation for other reasons, in patients likely to be

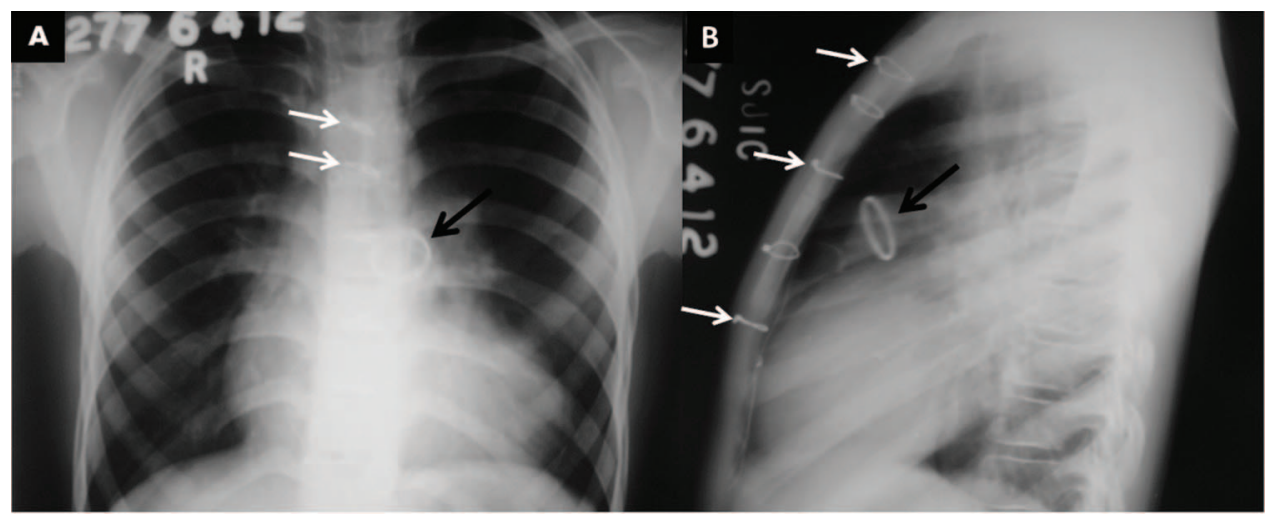

Figure 1 Chest radiography demonstrating metallic ring shadow (black arrows) in posteroanterior-view (A) which is confirmed to be in reterosternal pulmonary position in lateral view (B). Poststernotomy metallic suture wires are also seen (white arrows).
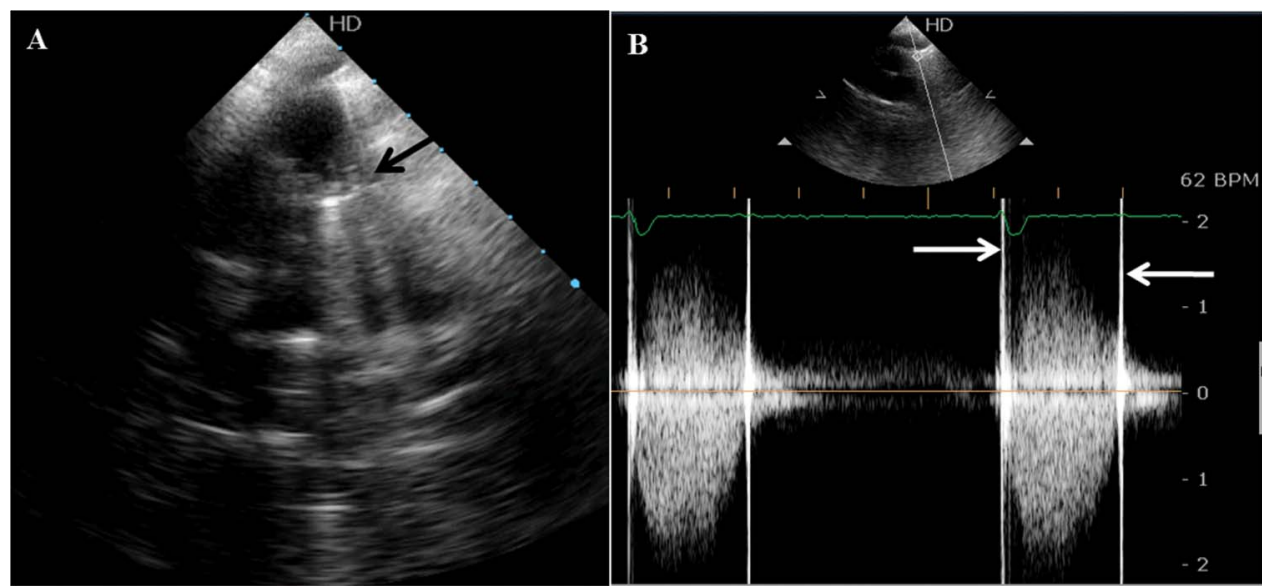

Figure 2 Two-dimensional echocardiogram demonstrating mechanical prosthetic pulmonary valve with acoustic shadowing (black arrow) in parasternal short axis view (A). Doppler interrogation (B) across the pulmonary valve showing doppler signals (white arrows) of opening and closure of mechanical prosthetic valve. 


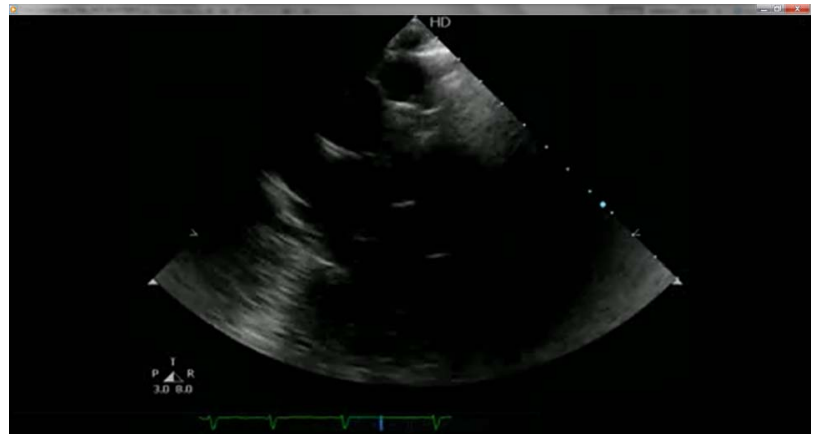

Video 1 Two-dimensional echocardiography in parasternal short axis view showing normal mobility of mechanical prosthetic valve at pulmonary position with acoustic shadowing.

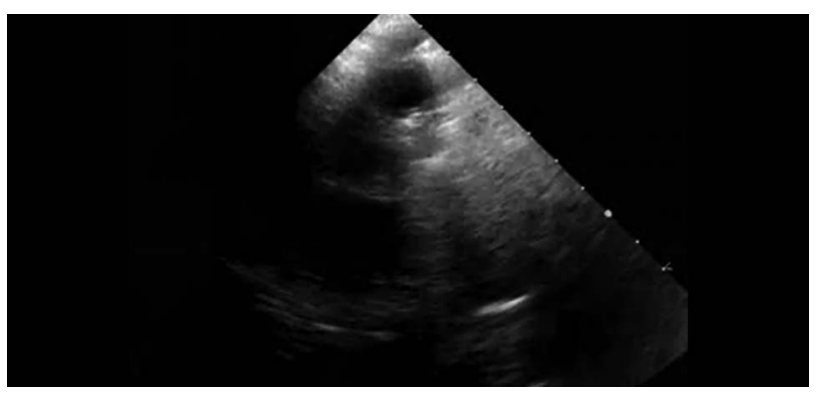

Video 2 Two-dimensional echocardiography in parasternal short axis view showing normal mobility of mechanical prosthetic valve at pulmonary position with acoustic shadowing.

compliant with long-term anticoagulation, and those in whom the risk of reoperation is deemed to be unusually high. ${ }^{2}$ In our patient, atrial fibrillation was the compelling indication for anticoagulation.

\section{Learning points}

- Pulmonary valve replacement is performed increasingly after correction of tetralogy of Fallot because of pulmonary regurgitation.

- Even though bioprosthetic valve are preferred, mechanical prosthetic valve can also be considered, especially when patient requires long-term anticoagulation for other reasons and/or the risk of reoperation is high.

Competing interests None.

Patient consent Obtained.

Provenance and peer review Not commissioned; externally peer reviewed.

\section{REFERENCES}

1 Williams WG. Surgical outcomes in congenital heart disease expectations and realities. Eur J Cardiothorac Surg 2005;27:937-44.

2 Waterbolk TW, Hoendermis ES, den Hamer IJ, et al. Pulmonary valve replacement with a mechanical prosthesis. Promising results of 28 procedures in patients with congenital heart disease. Eur J Cardiothorac Surg 2006;30:28-32.

Copyright 2013 BMJ Publishing Group. All rights reserved. For permission to reuse any of this content visit http://group.bmj.com/group/rights-licensing/permissions.

BMJ Case Report Fellows may re-use this article for personal use and teaching without any further permission.

Become a Fellow of BMJ Case Reports today and you can:

- Submit as many cases as you like

- Enjoy fast sympathetic peer review and rapid publication of accepted articles

- Access all the published articles

- Re-use any of the published material for personal use and teaching without further permission

For information on Institutional Fellowships contact consortiasales@bmjgroup.com

Visit casereports.bmj.com for more articles like this and to become a Fellow 